\title{
Being-in-the-City: A Phenomenological Approach to Technological Experience
}

\author{
By Jason Wasiak
}

\begin{abstract}
This paper examines dynamics surrounding the negotiation and articulation of the body-technology relationship necessarily characterizing the experience of beingin-the-city. Nowhere is everyday experience more mediated by technology than in the city. Being-in-the-city involves being embodied by technology at levels ranging from micro to macro. Despite the fact that technologies are constantly evolving in city space, relations with technology tend to become quickly normalized - mundane - transparent. Given this normalization as well as the sheer pervasiveness of technology in constituting city space it is important to examine the ways in which technology comes to shape the experiential contexts of everyday life. In urban space, technologies result is new sights to be seen, sounds to be heard, smells to be smelt, textures to be felt, as well as altogether new modes of experiencing the everyday. In exploring the dynamics surrounding the ongoing, multi-layered negotiation and articulation of the body-technology relationship necessarily characterizing the experience of being-in-the-city a phenomenological perspective is adopted. Heidegger's writing on technology, Merleau-Ponty's writing on embodiment and perception, and Don Ihde's writing on the body and technology contribute to a theoretical framework for a phenomenological examination of the experiential implications of being-in-the-city, a technological ecology.
\end{abstract}

Keywords: being-in-the-city, technology, embodiment, perception, phenomenology, technological ecology 


\section{Introduction}

Nowhere is everyday experience more mediated by technology than in the city. The city is an inherently technological environment, largely constituted through technology, and serving as a focal point for the ever-widening production, distribution, and consumption of technology. Thus, it might be said that what is fundamental to both the "city as sign" and "signs of the city" is technology. Technology is and always has been central to the city as reality, as image, and as symbol. In the broadest sense the city itself might be thought of as a technology that one is embodied by through inhabitation. By merely occupying a location within city space one is inherently enmeshed in a vast array of technological relations. In this sense, being-in-the-city necessarily involves a perpetual, multi-layered negotiation with technology at levels ranging from micro to macro. The most immediate site of this negotiation is in the relationship between the body and technology as one navigates everyday life in the city. The way in which this body-technology relationship is negotiated and articulated involves a constant reshaping of perceptual regimes, which holds profound implications for all other aspects of experience. Perceptual horizons are constantly being reworked in variety of ways through the everyday bodily engagement with technology, and this is particularly heightened in the technologically constituted environment of the city. The negotiation and articulation of the technology-body relationship in the everyday navigation of the city holds profound implications for the experience of space and time as well as all aspects of sensation. An overwhelming amount of what enters the senses within city space is a by-product of technology. In the city technology results in new sights to be seen, sounds to be heard, smells to be smelt, flavors to be tasted, textures to be felt, as well as altogether new modes of experiencing the everyday.

Despite the fact that technology is constantly evolving in city space, at the micro level our technological relations tend to become quickly normalized through everyday engagement-rendered mundane-receding into the background of day-to-day experience. This tends to conceal their import. As such, this paper examines dynamics surrounding the ongoing, multi-layered, negotiation between body and technology necessarily characterizing the experience of beingin-the-city. While it is acknowledged that interactions with technology in city space are vast and heterogeneous in nature-culturally variable and shaped by one's social location-what is focused on here is the primacy of the negotiation and articulation of the body-technology relationship necessarily characterizing the navigation of everyday life in the city. To this end, a phenomenological perspective is adopted. In particular, Heidegger's writing pertaining to technology, Merleau-Ponty's writing pertaining to embodiment and perception, and Don Ihde's writing pertaining technology and the body contribute to a theoretical fra- 
mework for a phenomenological examination of the experiential implications of being-in-the-city, an inherently technological environment.

\section{Conceptualizing Technology}

As technology is being upheld as an essential feature of the city, and as it is being suggested that the negotiation and articulation of the body-technology relationship is primary to the experience of being-in-the-city, it is necessary to unpack the term technology before proceeding further. As a word, technology tends to be used in everyday discourse with such ubiquity that its particular meaning often remains quite vague. Its roots are those of the Greek techne, often referring to art or craft knowledge (as distinguished from epistēme, or theoretical knowledge), and logos, referring to discourse. Thus, in this sense technology refers to discourse or knowledge of art or craft production. However, Heidegger (1977) notes that for the Greeks technē belongs to poiesis-a bringing-forth out of concealment. As such, techne refers not to art or craft knowledge but rather means “...to make something appear, within what is present, as this or that, in this way or that way" (Heidegger 2001: 157). In its most everyday usage, technology tends to refer to those non-naturally occurring things resulting from the discourse or knowledge of art or craft production - that is, those built things that have been made to appear in particular ways and which serve as means to ends.

Kline (2003), in observing both the ubiquity and vagueness surrounding the usage of the word technology, points out that it has come to refer simultaneously to "...things, actions, processes, methods, and systems" (210). He draws attention to four predominant usages of the word technology. The first, and perhaps most common usage (as mentioned above), is in reference to non-natural hardware or artifacts manufactured by humans. The second usage is in reference to sociotechnical systems of manufacture, including all elements that go into the creation of any given artifact (labour, machinery, physical, economic, political, legal environments). The third usage observed is in reference to knowledge, methodology, technique, or "know-how". And the fourth usage that Kline (2003) points to is its reference to sociotechnical systems of use, which include combinations of artifacts and people (among other elements) that allow humans to perform tasks that they would otherwise be unable to, thus extending their capacities. Kline (2003) suggests it is of particular importance to understand technology in terms of sociotechnical systems of manufacture and sociotechnical systems of use, for it is within these overarching systems that particular techniques and artifacts are embedded.

Very often technology is thought of as simply a means to ends (instrumental definition); however, the true accuracy of this characterization as a linear relationship has been contended. As Jonas (2003) notes, with modern technology this means-ends relationship is less linear than it is circular. He observes that as a 
process, modern technology tends not toward equilibrium, but rather ceaselessly generates new directions for subsequent innovations, and that innovation tends to spread rapidly facilitated by technology and insured by competition. These processes are particularly accelerated by the proliferation of communication technologies and felt most intensely in city space. Jonas (2003) suggests that as a result of these features "progress" is an inherent drive of technology, not merely an ideological concept, insomuch as it builds on that which came before. Stiegler (1998) echoes this writing: "Technical progress consists in successive displacements of its limits" (33). He goes on to write: "Innovation accomplishes a transformation of the technical system while drawing the consequences for the other systems” (Stiegler 1998: 36). With both Jonas (2003) and Stiegler (1998) attention is drawn to fundamental ways in which technology opens up new possibilities for further innovations with new sets of limits and consequences (some which are intended and/or foreseen while many are not).

Heidegger (1977) interrogated the fundamental accuracy of the instrumental definition of technology as merely a means to an end in The Question Concerning Technology. He observed that while the instrumental definition of technology is at some level correct it does not yield the most accurate insight into the essence of modern technology. The essence of modern technology, for Heidegger, is itself nothing technological, but rather it is a process of "challenging-forth" the "standing-reserve" (Bestand) of nature. This is perhaps put most simply in Heidegger's (1966) Memorial Address where he writes: "Nature becomes a gigantic gasoline station, an energy source for modern technology and industry” (50). For Heidegger (1977) the essence of modern technology cannot be reduced to mechanics and individual human activity. It is rather the all-pervasive process of "challengingforth" into "ordering” as a particular mode of "revealing”. It is a preoccupation with "unlocking”, “transforming”, "storing”, "switching about ever anew” and "distributing" that which is concealed in nature and might be put to use. Heidegger (1977) uses the word Enframing (Ge-stell) to describe the type of ordering that sets about this “challenging forth". Stiegler (1998), echoing Heidegger, characterizes the move to modern technology, writing: "Technics commands (kbernaô, the etymon of cybernetics) nature. Before, nature commanded technics. Nature is consigned by technics in this sense: nature has become the assistant, the auxiliary; in similar fashion, it is exploited by technics, which has become the master" (Stiegler 1998: 24). Implied here is the double meaning of "ordering”: "to command" as well as "to arrange". We can conceptualize the city as a space that is most exemplary of these processes of "challenging forth" into "ordering", where processes of "unlocking”, "transforming", "storing”, and "switching about ever anew" manifest themselves in the densely layered technological networks through which one navigates everyday life.

Heidegger's (1962) earlier discussion in Being and Time of "The Being of the Entities Encountered in the Environment” also yields numerous relevant points of 
consideration in foregrounding the present discussion. Here, Heidegger discusses dynamics surrounding our relationship to equipment [Zeug], as we encounter it in our everyday experience. He notes that in our everyday dealings we encounter equipment for writing, sewing, working, transportation, measurement, etc.; and that at the most fundamental level equipment is "something in-order-to". In this "in-order-to" structure resides an assignment or reference of something to something else within a referential whole. The oft-quoted example he gives is the use of a hammer for hammering. In discussing this example Heidegger points out the extent to which "putting-to-use" "in-order-to", constitutes the type of being that equipment possesses as a "readiness-to-hand" [Zuhandenheit]. And furthermore, that the more one grabs hold of the hammer and puts it to use, "the more primordial does our relationship to it become” (Heidegger 1962: 98). Dreyfus (1990), in his commentary of Being and Time, further notes that: "When we are using equipment, it has a tendency to "disappear". We are not aware of it as having any characteristics at all” (64). In what Dreyfus calls absorbed coping, the awareness of equipment recedes into transparency as one becomes absorbed in the task at hand with the skillful implementation and smooth functioning of that equipment.

Heidegger (1962) goes on to point out that when equipment breaks-down or is somehow found to be unusable ("un-ready-to-hand"), that it is at this precise moment that the equipment in relation to the referential whole is made conspicuous. We are made aware of our relationship to the equipment and its relationship to the referential whole, an awareness that had receded into the background in the skillful implementation and smooth running of the equipment. As he writes: "When equipment cannot be used, this implies that the constitutive assignment of the "in-order-to" to a "towards-this" has been disturbed... when an assignment has been disturbed - when something is unusable for some purposethen the assignment becomes explicit” (Heidegger 1962: 105). Dreyfus (1990), in further characterizing this writes: "Temporary breakdown, where something blocks ongoing activity, necessitates a shift into a mode in which what was previously transparent becomes explicitly manifest. Deprived of access to what we normally count on, we act deliberately, paying attention to what we are doing” (72).

In light of the above, a number of premises might be established for the present discussion: a) being-in-the-city is characterized by a ongoing negotiation with an ever-expanding relational totality of equipment, which one necessarily engages with as a part of everyday coping (or merely occupying a location within an urban space for that matter). This ever-expanding relational totality is a result of dynamics observed by Jonas (2003) and Stiegler (1998) as an essential feature of technology; b) one's necessary engagement or negotiation with technology in city space is something that becomes increasingly normalized, transparent, and primordial through everyday use, familiarity, or habit; and c) insomuch as one is 
necessarily surrounded by technology at every turn in the city, the breakdown or otherwise un-readiness-to-hand of equipment (at levels ranging from micro to macro) is also an everyday aspect of navigating the urban landscape, where otherwise normalized/transparent/primordial relations render themselves conspicuous in their un-readiness-to-hand.

Don Ihde's (1990) phenomenology of technics, which builds on insights from Heidegger and Merleau-Ponty, provides further points of relevance in prefacing a discussion of the dynamics characterizing the navigation of the city. Here Ihde defines technics as: “...the symbiosis of artifact and user within a human action” (Ihde 1990: 73). In his phenomenology of technics, Ihde puts forth several existential relations that we have with technology, including: embodiment relations, hermeneutic relations, alterity relations, and background relations. Embodiment relations describe the way in which technology comes to be taken into the body and factored into one's experiencing of the world. An example he gives is the relationship one has to eyeglasses: the "I-glasses-world" relationship, through the normalization of experiencing the world through the eyeglasses, comes to be rewritten as “(I-glasses)-world”. As Ihde (1990) writes, with embodiment relations, "...I take the technologies into my experiencing in a particular way by way of perceiving through such technologies and through the reflexive transformation of my perceptual and body sense” (Ihde 1990: 72). Insomuch as this experiencing through technologies becomes increasingly normalized the technology becomes increasingly "transparent". Furthermore, the better fit the technology is in relation to the body and the task at hand the more likely it is to recede into the background of awareness. Ihde's notion of hermeneutic relations is where technologies are understood as something to be read and interpreted. As he writes: "Readable technologies call for the extension of my hermeneutic and "linguistic" capacities through the instruments, while the reading itself retains its bodily perceptual location as a relation with or towards the technology" (Ihde 1990: 88). He later writes: "Through hermeneutic relations we can, as it were, read ourselves into any possible situation without being there” (Ihde 1990: 92). With alterity relations technology becomes the other or quasi-other to which one relates. In addition to these three variations Ihde (1990) also discusses background relations, noting that when technologies operate in the background the "withdrawal" of its overt presence manifests itself as a sort of present "absence", where the technology operates as if it were "to the side”. It is, however, still part of one's experiential field albeit, by definition in the background.

Ihde's phenomenology of technics and the genealogical line of thought from which it was derived (namely Husserl, Heidegger, and Merleau-Ponty) provide a very rich point of entry in thinking about the experience of being-in-the-city, which at any given moment is characterized by a complex, multi-layered texture of these relations, and which in their familiarity often come to be normalized and rendered transparent. What could be extended in Ihde's account is the nuanced 
way in which these relations are constantly being negotiated and are in constant flux. The navigation of the technologically constituted environment of the city necessarily involves dense layers of these relations at any given moment, and we often slip between them from one moment to the next. These relations may be more or less complex and densely layered at any given moment, and may appear to vary as such depending on the way in which they are viewed. Very often awareness of these relations recedes into the background of everyday experience in their normalization.

One last point of contextualization with respect to conceptualizing technology: As Nardi and O’Day (1999) point out the very language we use to describe our relationship to technology tends to colour our perception of it. At the most general level they note (as many others have) that to a large part discourse surrounding technology tends to take place along a utopian versus dystopian spectrum. Furthermore, they point out the extent to which the metaphors that are commonly used to describe our relationship to technology come to shape our perception of that relationship in a variety of ways-at times illuminating it and at times obscuring it. Among the more common metaphors observed are: technology as tool, technology as text, technology as system, and technology as ecology (all of which were operating implicitly in various places above). They suggest that describing technology as a tool involves viewing it as a means to an end (the instrumental definition) and tends to imply one's control or mastery over it. Technology as a text involves viewing technology as carrier of meaning-something to be read and interpreted in order to understand its imperatives in different social settings. Technology as a system tends to involve the perception of the inextricable and relentless quality of technological change, and the sense of being caught up inside of it. And the metaphor that they are in most favour of is that of technology as ecology. As they note this metaphor tends to promote the view of being “...surrounded by a dense network of relationships in local environments". (Nardi \& O’Day 1999: 27). The metaphor of technology as ecology, thus, tends to afford a greater degree of agency among all actors in the environment and is somehow fitting with the notion of technics as the symbiotic relationship between body and technology. The notion of technology as ecology also seems particularly appropriate in thinking about being-in-the-city-for what is a city if not a technological ecology? Implied in this term is both the organic and mechanic-the movement of bodies with, within, and in relation to technology at a variety of levels within the multi-layered technological environment that is the city.

\section{Building and Dwelling: The City as Technological Ecology}

Insomuch as ecology deals with the relationships and interactions of organisms with each other and their environment, it seems appropriate to think of the city as a technological ecology. The environment of the city is comprised 
overwhelmingly of technology, and thus being-in-the-city necessarily involves being enmeshed in a complex, multi-layered, symbiotic relationship with technology that is constantly negotiated and in constant flux. As Lash (2002) notes: "I operate as a man-machine interface - that is, as a technological form of natural life-because I must necessarily navigate through technological forms of social life" (15). As the environment of the is city is overwhelmingly a technological one, practically every bodily movement involves layers of relations with technology that are more or less to the foreground of one's awareness at any given moment. Kittler (1996) speaks to the multi-layered-ness of the city in terms of networks, writing: "In a city, networks overlap upon other networks. Every traffic light, every subway transfer, and every office, as well as all the bars and bordellos, speak for this fact” (719). The city is comprised vast layers of networks-economic networks, social networks, political networks, transportation networks, information networks, plumbing networks, electrical networks, etc. All of these networks are, in some way, part of what Kline (2003) observed as sociotechnical systems of manufacture and sociotechnical systems of use. Manufacture and use correspond roughly to what might be among the most primary activities governing city space: namely, building and dwelling.

The city as a technological ecology is fundamentally characterized by building and dwelling. Heidegger (2001), in his essay Building Dwelling Thinking, examines the relationship between these activities, asking: "What is it to dwell?" and "How does building belong to dwelling?" (143). He observes that dwelling is something attained through building, and that building has dwelling as its goal. In this sense he provisionally notes that building and dwelling are related as means to ends. However, in a similar wariness exemplified in The Question Concerning Technology, where the instrumental definition of technology as simply a means to an end was interrogated as to its essential accuracy, here too the means-end schema is seen to obscure the essential relations of building and dwelling. For as Heidegger (2001) notes: “to build is in itself already to dwell” (Heidegger 2001: 144). He suggests that while not all buildings are dwellings, that they belong to the domain of dwelling. While things such as bridges, hangars, stadiums, power stations, railways stations, highways, dams, market halls, etc. are not dwellings (in the narrower sense), that: “These buildings house man” (Heidegger 2001: 144). Nowhere are building and dwelling more concentrated than in the city, and the way in which building and dwelling are articulated in city space necessarily shapes one's experience of the city.

As an organic body dwelling in the technological ecology that is the city, one is necessarily engaged in an ongoing, multi-layered negotiation with technologies from the very moment waking. As Ihde (1990) writes: "It is likely that we are called into waking consciousness by a technology, be it the ringing of an alarm, the beeping of a quartz clock, or the sounds of a clock-radio" (1). Ihde goes on to note the vast array of mundane technological objects that we are likely to engage 
with in the first hour of waking alone: beds, blankets, bathrooms, plumbing systems, kitchen appliances, moving outward to transportation systems, automobiles, etc., all of which are the genesis of particular technological trajectories, embedded in socio-technical systems of manufacture and socio-technical systems of use, and all of which in our interaction with them involve a negotiation. Implied in the term negotiation, is the way in which interactions with technology are inherently two-way relations. Ihde (2002) points to this, writing: “...all human-technology relations are two-way relations. Insofar as I use or employ a technology, I am used by and employed by that technology as well” (137-138).

As city space is comprised overwhelming of technology, this negotiation is particularly unavoidable. Moving around in the city necessarily involves navigation amidst the technologies that comprise the landscape, such as: buildings, sidewalks, streets, bridges, traffic lights, streets signs, street lamps, telephone poles, electrical and telephone wiring, advertisements, TV screens, etc. It is also a negotiation with those technologies that one grabs hold of and implements in everyday dealings such as keys, doors, tools, pens, books, computers, bags, mobile phones, maps, etc. There are also those technologies that are taken into one's bodily experience of the environment, such as shoes, clothing, eyeglasses, and various other prosthetics. And there are those technologies operating in the background at all times, such as: electrical grids, information networks, plumbing systems, thermostats, etc.

My own present mundane experience exemplifies one particular articulation of this multi-layered technological negotiation. Right now I am sitting in a room, in a building, in the city. ${ }^{1}$ In this sense, I am literally inside of technology at a variety of different levels. Practically every aspect of my perceptual field is currently engaged with technology and my bodily posture and movements are shaped by the negotiation with things such as my clothing and the chair that I am sitting on in relation to the table that I am sitting at and the computer that I am typing on. I am currently listening to music with headphones; however, the volume is quite low and thus it is rather unobtrusive. This aspect of the soundscape seems to meld with the low white noise of the ventilation system, whose cool air currents make themselves known to my bare arms. At a certain point the coolness of the air circulating within the microclimate of the building prompts me to put on a sweater. I am sitting directly in front a large window and the view consists almost entirely of concrete, steel, glass. The vast majority of the frame is dominated by building structures. In the upper right portion of the window frame there is one building that has been embodied by an exoskeleton of scaffolding, and to the far right a large mechanical crane pivots in and out of the window frame, exemplifying the city's fundamental preoccupation with building.

I am necessarily engaged in a multi-layered negotiation with technology. The most immediate site of my negotiation amidst these dense networks of technological relationships is the body, and the way in which the body-technology 
relationship is negotiated involves a constant reshaping of perceptual regimes, which is simultaneously both mundane and profound. Merleau-Ponty (1962) implicitly articulates both mundane and profound aspects of this relationship, writing: "Habit expresses our power of dilating our being-in-the-world, or changing our existence by appropriating fresh instruments" (166). It is through our everyday engagement with technologies that our relationship to these things comes to be normalized, rendered mundane, habitual, familiar, and transparent; however, the way in which this relationship is negotiated involves a reshaping and dilation of our particular way of being-in-the-world.

\section{Moving Around In The City}

Being-in-the-city involves movement. The dilation of our being-in-the-world through the appropriation of instruments can be exemplified by examining the negotiation between technology and the body in the various modes of moving around in the city. This negotiation takes place at various levels of awareness, with varying degrees of foregroundedness or backgroundedness and may be more or less complex and multi-layered at any given moment. The variety of ways in which bodies move throughout the city exemplify technological variations that are simultaneously mundane and profound. The way in which the technology-body relationship is negotiated and articulated in one's everyday going about the city holds significant perceptual and thus epistemological implications. Kingwell (2008) acknowledges the link between epistemology and lived urban spaces writing: “...epistemology and philosophy of mind are further linked to the real grids and spaces that we conscious entities occupy, the streets and places of actual cities. Epistemology is architecture, and architecture epistemology, because both concern our experience of the world as space" (24). Kingwell (2008) attends to the way in which the bodily experience of urban space comes to shape consciousness, while acknowledging the mutually constituted nature of this relationship. As he writes: "Consciousness shapes cities. They are built places, the results of human imagination and planning... Cities also shape consciousness then, becoming the places of our dwelling and occupation and love affairs. They house our thoughts and guide our flow" (Kingwell 2008: 136).

In thinking about the various ways in which the technology-body relationship is negotiated in moving about city space we can juxtapose several common modes of travel that are mediated differently and to greater or lesser degree by technology. Among them: walking, cycling, driving, and riding the subway. In doing so perceptual, experiential, and epistemological implications (all of which intersect with one another) are revealed. The particularities of any city space in terms of layout, geography, and infrastructure lend themselves more or less to particular modes of moving around, and this is certainly a major consideration and point of contestation for urban planning. At a more primary level, however, an account of 
technological variations of moving about the city yields insight into perceptual implications surrounding the negotiation of the body-technology relationship.

When one is walking in the city movement is, to a large part, shaped by the negotiation of things like sidewalks, streets, traffic lights, cars, buildings, other people, the city's layout, geography, etc. It is also a negotiation that takes place with such mundane (but nonetheless technologically sophisticated) things as shoes and clothing and the appropriateness that they hold in relation to my body for the task of walking, as well as the relative distance between things, and the ease or difficulty of geographic features in relation to the suitability of one's body to get around this way. Walking in its slowness holds different perceptual possibilities for the experience of the urban landscape. The potential ability to attend to microlevel details of the environment in the slow scrolling cityscape is vastly expanded when walking as opposed to faster moving modes of transportation. Things may be noticed that would otherwise be perceived only as a blur or not at all with different modes of travel. Details from street level detritus to insects or birds on the sidewalk to the endless stream of signs and advertisements seeking one's attention are all available in a way that may be obscured by different modes of movement. Attention is freed to a greater or lesser degree based on immediate obstacles such as density of other walkers, car traffic, cyclists, etc. One's body is vulnerable to the natural elements (wind, rain, snow, hot or cold temperatures, etc.), mediated only by clothing. It is also more vulnerable to other hazards such as traffic. Walking as a mode of perception has different temporal and spatial limits than other more technologically mediated forms that extend the bodily potential in terms of distance and speed. Walking in the city, while certainly a less technologically mediated or extended as an articulation of the body-technology relationship, still very much involves a complex and multi-layered negotiation with technology at a range of levels.

Moving around the city by bicycle steps up the level of integration between body and technology, mechanically extending the natural capacity for movement of the body. As McLuhan (1967) famously observed: "The wheel is an extension of the foot” (31-32). One's body is no longer in direct mediation with the street but now by shoes on pedals attached to a crank, moving gears that turn wheels encased by inflated rubber tires - the new point of mediation with the street. Bodily capacities here are greatly extended as speed and distance are relativized accordingly. There is a speed and flexibility afforded to riding a bicycle that in many instances prove advantageous to either foot or car travel in crowded city spaces. There is still a certain unmediated intimacy with the environment but the technological extension of speed results in a very different perceptual experience. Visual details that are perceptible while walking pass by in a blur on a bicycle; and one is necessarily drawn to attend to different things while cycling than walking. There is a bodily vulnerability that is possibly increased from walking in that one is often dealing more intimately with car traffic. There is still an 
immediate contact with the environment that is further mediated with other forms of travel, though the experience of that environment is quite different than when walking. The coupled increase in speed and intimacy with the environment changes the way one experiences the air - the air is tangible as a thickness directly correlated to speed.

When fully absorbed in the act of cycling there is a truly remarkable symbiosis between body and technology. In the skillful navigation of city streets by way of bicycle one's awareness of the relationship to the technology tends to recede into the background when all things are functioning fluidly. This relationship may be rendered conspicuous in the instance of some form of equipment failure (which may range from subtle to drastic). However, when things are functioning smoothly there is a remarkable unity between bicycle and body-the bicycle becomes an extension of the body. What is further remarkable about the bodytechnology negotiation in the instance of cycling is the extent to which it exemplifies a very deep type of bodily memory that is much more about movement than conscious retention. The popular simile "It's just like riding a bike" pays testament to the fact that one seems to retain a kind of deep-rooted bodily memory of how to ride a bicycle even after the passage of extended periods of time. Merleau-Ponty (1962) alluded to a similar kind of bodily memory in his discussion of habit, with the example typing. As he writes: "It is possible to know how to type without being able to say where the letters which make the words are to be found on the banks of keys” (166). In both cycling and typing (as with many other body-technology relationships) there is a type of bodily memory at work that is very different from that of active conscious recall.

The symbiosis of body-technology is differently exemplified in driving a car. This variation of technologically mediated movement yields further insight into the perceptual implications in the negotiation of this relationship. In a car, as opposed to walking or cycling, one's body is literally inside the technology, and thus there is further technological mediation one's experience of the environment. There exists a microclimate within the car that can be manipulated in ever more sophisticated ways. In this sense there is an inside and an outside lacking in the previous variations. Driving a car involves several of Ihde's (1990) relations with technology layered simultaneously. Being-in-a-car is an embodiment relation insomuch as one is embodied by the car, experiencing the space through the car. There are at once a number of background relations (the thermostat, the smooth running of the engine, suspension, etc.); hermeneutic relations are exemplified explicitly in the numerous gauges on the dashboard that are there to be read; and my relation to other cars on the road is certainly one of alterity. Furthermore, it can be said that these relations are anything but static - they are complex, multilayered, and in constant motion. Depending on how the body-technology relationship is being negotiated one may slip between these relations from one moment to the next. For instance, there is a move from embodiment relation to 
alterity relation in stepping out of the car. Furthermore, in the instance of breakdown, the transparency of embodiment and background relations in the flow of skillful coping and smooth running of the technology immediately become alterity and hermeneutic as the point of failure requires diagnosis.

When driving in the city there are an astonishing number of considerationsone must attend to a great number of variables and the margin for error is very little. However, the more one drives in the city the more these complex layers of variables recede into the background as a result of an absorbed skilful coping. One is able to navigate remarkably tight parking spaces and dense traffic that tend to characterize city driving. Again this speaks to a certain unity achieved in the technology-body relationship, where the body here has taken on the exoskeleton of the vehicle extending it dramatically in terms of bodily capacities and temporalspatial relations. Merleau-Ponty (1962) alludes to the ability to navigate space intuitively with bodily extensions in his discussion of habit, specifically citing the example of driving. As he writes: "If I am in the habit of driving a car, I enter a narrow opening and see that I can 'get through' without comparing the width of the opening with that of the wings, just as I go through a doorway without checking the width of the doorway against that of my body [107]" (165). Here, Merleau-Ponty (1962) notes that one's experience of space is not that of objects with specific measurements (volume and size), rather one experiences these things as "potentialities of volume" in relation to "the demand for a certain amount of free space” (165). Again, we see a certain symbiotic unity achieved between technology and body. This too relates to Ihde' s (1990) notion of technological transparency achieved in embodiment relations, which itself was much related to Heidegger's discussion of familiarity and the skilful coping with equipment in the environment.

Another variation of technological movement about the city, which further exemplifies the perceptual implications of the negotiation of body and technology, is that of riding the subway. Being-in-the-subway one is once again embodied by technology, although unlike driving a car one relinquishes control over the vehicle's movement. As a result there are fewer immediate demands on one's attention than when cycling, driving, or walking. As a result of these different attentional demands, and the fact that one is travelling below ground, moving about the city this way has whole different set of perceptual implications. When riding the subway one enters at a particular point in the system, negotiating turnstiles, token slots, card-swiping machines, crowds of people (which ebb and flow depending on the particular time of day). One descends beneath the ground where one is denied perceptual access to the above ground geography; thus, this mode of travel is characterized by large blind spots in above ground geography.

In thinking beyond the specific negotiation and perceptual implications of these particular modes of moving about the city, the related concepts of familiarity (Heidegger) and habit (Merleau-Ponty) further illuminate the way this body- 
technology negotiation takes place in time. Aside from the particular mode of travel, it is certainly a very different experience to navigate an urban space for the first time as opposed to those routes that one takes on a regular basis. Navigating unfamiliar city space is usually hermeneutic relations (maps, directions, signs, etc.) contributing to one's spatial orientation, while navigating the familiar spaces of the everyday tends to happen almost unconsciously. Insomuch as the city itself may be viewed from the macro level as a technology that one is embodied by and in constant negotiation with, what Heidegger observes with his hammer example (that the more one grabs hold of it and puts it to use the more primordial does this relationship become) might also be extended to the way that we experience everyday movement within the city in terms of familiar or unfamiliar spaces. The more we put the city to use as a technology in our everyday dealings with it, the more primordial does this relationship become; and the more the equipment that are involved in the everyday navigation of the city recede into the background. In navigating unfamiliar urban space, the city as a technology is experienced as an "un-readiness-to-hand". Relationships that recede into transparency as a result of their familiarity (through the everyday usage of specific routes and modes of transportation) are rendered conspicuous in the un-readiness-to-hand of unfamiliar spaces.

\section{Experiencing Architectural Space}

In the city everyday movement is the movement within and between architectural structures necessarily involving the negotiation of thresholds. As Kingwell (2008) writes: "The threshold is an ontological anomaly, a space outside of space, existing only in its vanishing... The function thus of the threshold, therefore, is not to be wide but to separate, and thus to be crossed" (158). Architecture, at a fundamental level, is about the construction of boundaries that delineate and thus create space. Structures themselves have thresholds that are more or less permeable to different things (i.e. bodies, light, sound, air, etc.). They determine what constitutes the private vs. the public and often due to the permeability of boundaries this distinction is blurred or intruded upon.

Kingwell (2008) acknowledges the extent to which the concept of the threshold is one that governs not only the creation of architectural structures and thus meaningful space, but also the fundamental way in which it is a feature of consciousness itself. He writes: "The logic of inside and out belongs to us all—not only because we all must live with and in buildings, those monuments to human desire, but also because, and more profoundly still, it structures consciousness itself” (Kingwell 2008: 93). Thus, we can think of the perpetual crossing of thresholds not only in terms of something that characterizes ones bodily movement in space, but also in the way that this is closely related to the experiential dimensions of communication, perception, and consciousness. 
Kingwell (2008) sees the act of crossing thresholds, something that we are doing all the time in moving about the city, as being closely related to Heidegger's notion of Zuhandenheit (readiness-to-hand). As he writes: "Indeed, the mundane act of unself-conscious crossing is a good example of what Heidegger means by Zuhandenheit, the readiness-to-hand of potentially revealing acts or spaces, whose revelatory possibilities are held in check by their very everydayness" (Kingwell 2008: 158). The myriad of structural thresholds that mark out and create space at every turn in the city is certainly exemplary of the vast and complex technological infrastructure that is the physicality of the city in terms of its architectural space. It is also very much true that at the most fundamental level in our everyday going about the city the conspicuousness of these architectural boundaries tend to recede into the background of awarenessparticularly in those spaces most familiar. Again, Heidegger's notion of the readyto-hand [Zuhandenheit] speaks to the experience of crossing thresholds in architectural space. Just as it was noted that the more the hammer is put to use the more primordial and transparent is one's relation to it become, so too might this be said about the navigation of thresholds in urban space. Heidegger's observation of the conspicuous of breakdown or otherwise un-readiness-to-hand also shows itself here. Familiarity and habit tend to result in the transparency of thresholds in the everyday navigation of city space. These thresholds render themselves conspicuous in breakdown or otherwise un-readiness-to-hand (ie. broken lock, misplaced keys, etc.).

There is also the permeability of boundaries in city space. The proliferation of communications and communication technologies in city space tends to result in the increasing permeability of boundaries that delineate private from publiccommunication spills. This is something that has become increasingly apparent with the proliferation of mobile phones. Conversations that prior to this technology would have been more contained within the private space of the home or office spill into public space. And in terms of the home, sounds from the street or noisy neighbours, unwanted telemarketers, etc., permeate the boundaries of private space illuminating the differing types of thresholds. Again here, the way in which the technology-body relationship is negotiated reshapes the types of things to enter into one's perceptual field and the modes through which one perceives them.

\section{The Mediated City}

The movement of information throughout the urban environment is constantly reshaped by technology holding profound implications in terms of one's experience of space and time. As McQuire (2008) observes: "The intermeshing of digital technology with urban terrain has produced a new set of pressures with both centripetal and centrifugal trajectories” (McQuire 2008: 20). One's movement and experience of the city is increasingly characterized by an engagement with a wide 
variety media-both those that are part of the cityscape as well as those that accompany the body in the everyday going about the city. Kittler (1996) goes so far as to note the extent to which the city as a whole can be seen as a medium. As he writes: "MEDIA record, transmit and process information-this is the most elementary definition of media. Media can include old-fashioned things like books, familiar things like the city and newer inventions like the computer" (Kittler 1996: 722). At the micro level, being-in-the-city involves the ongoing negotiation with and navigation through increasingly mediated spaces. The everincreasing plethora of communication devices that people tend to engage with comes to characterize, texture, and give shape to everyday experience in the contemporary city. The way in which one interacts with media in the city necessarily involves a reshaping of perception (both in terms of those things to be perceived as well as opening up entirely different modes of perception), which profoundly impacts the experience of space and time; however, this experience tends to be quickly normalized, again rendered transparent, through regular engagement.

The increasing proliferation of communication technologies, most heightened in urban space, is a manifestation of what Jonas (2003) observed as the circular means-end relationship of modern technology and its capacity to generate ceaseless new direction for innovation. Also, communication technologies themselves are unique in that they allow for the capacity to accelerate the spread of innovation, further accelerating these processes. A result of the ever-increasing proliferation of communication technologies has been a qualitative shift in the nature of information. Borgmann (2003) observes this drawing the distinction between information about reality, information for reality, and information as reality, noting: "Traditionally, information has been about and for reality. But through the technological developments of the past century and a half, information, though still about and for reality, also has begun to rival reality, itself; and has emerged virtually as reality" (Borgmann 2003: 573). Information as reality it would seem has resulted from the genesis of both information for and information about reality and has become perpetually expansive. The experiential implications of this hold significant considerations in the navigation of urban space.

The contemporary city is, as McQuire (2008) notes, a media-architecture complex that profoundly reshapes perceptions of time and space. McQuire (2008) testifies further to this writing: "Dwelling in a space-time framed by a proliferation of media technologies fundamentally alters human sensory and perceptual parameters, sustaining a range of encounters which questions the limits of the body and the authority of embodied perception” (McQuire 2008: 10). Here McQuire (2008) attends to the primacy of the body and the perceptual implications involved in the negotiation of the body-technology relationship within increasingly mediated city space. McQuire's (2008) broad argument is that the pervasiveness of media in urban space coupled with tendencies of convergence, mobility and instantaneity "become a constitutive frame for a distinctive mode of 
social experience” (vii). As he writes: “...the spatial experience of modern social life emerges through a complex process of co-constitution between architectural structures and urban territories, social practices and media feedback”. (McQuire 2008: vii). For McQuire, the proliferation of media in the urban environment results in the creation of "hybrid spatial ensembles". The ways in which the bodytechnology relationship is negotiated in relation to ever-expanding forms of media comprising the cityscape holds profound perceptual implications for how we orient ourselves in space and time. As McLuhan (1967) was apt to point out: "Media, by altering the environment, evoke in us unique ratios of sense perceptions. The extension of any one of these senses alters the way we think and act - the way we perceive the world.” (26-41).

\section{Conclusion}

The city is an everyday environment constituted through technology and characterized by the continual proliferation of technology. As such, the city, more than any other space, might be thought of as a technological ecology, where one's relationship to the environment (and increasingly to others) involves a myriad of technological relations. In the city one is necessarily enmeshed in a complex and densely layered set of technological relations that are in constant flux as one moves about the city and as a result of perpetual technological changes in the urban environment. These relations may be more or less complex and densely layered and more or less foregrounded in one's awareness at any given moment. The most central argument that has been put forth in this paper is that fundamental to the experience of being-in-the-city is an ongoing, multi-layered, negotiation with technologies at levels ranging from micro to macro. The most primary site of this negotiation is the body-technology relationship, which is constantly being renegotiated as one moves throughout urban space amidst and with a variety of technologies. The way in which the body-technology relationship is negotiated and articulated holds profound perceptual implications both in terms of those things that enter one's perceptual field as well as the very mode through which they are perceived. The everyday engagement with technology in the urban environment tends to result in a normalization and transparency of body-technology relations, receding into the background of awareness, rendering themselves explicit, manifest, or conspicuous in the instance of breakdown or failure. Insomuch as being-in-the-city necessarily involves the navigation of complex and dense layers of technological relations at every turn it has been suggested that what is fundamental to both the "city as sign" and "signs of the city" is technology-that technology is and always has been fundamental to the nature of the city as reality, as image, and as symbol. 
Jason Wasiak is a Ph.D. student in communication and culture at York University and teaches part-time in the sociology department at Ryerson University. His current research interests revolve around the primacy of the relationship between the body and technology in characterizing everyday experience.

\section{Notes}

1 The room that I am sitting in is on the 4th floor of the Toronto Reference Library, and the table that I am sitting at is in front of a large window overlooking the cityscape facing Yonge Street, which currently holds the title of the "longest street in the world".

\section{References}

Borgmann, Albert (2003): "Information and Reality at the Turn of the Century", Robert Scharff \& Val Dusek (eds): Philosphy of Technology: The Technological Condition, Malden, MA: Blackwell Publishing, 571-577.

Dreyfus, Hubert (1990): Being-in-the-world: A commentary on Heidegger's Being and Time, Division 1, Cambridge, MA: MIT Press.

Heidegger, Martin (1962): Being and time (J. Macquarrie. \& E. Robinson, trans), San Francisco: Harper Collins Publishers.

Heidegger, Martin (1966): Discourse on thinking, New York: Harper Torchbooks.

Heidegger, Martin (2001): "Building dwelling thinking”, Poetry, Language, Thought (A. Hofstadter, Trans.) (pp. 141-159). New York: HarperCollins.

Heidegger, Martin (1977): The Question Concerning Technology and Other Essays, New York: Harper Torchbooks.

Ihde, Don (2002): Bodies in Technology, Minneapolis: University of Minnesota Press.

Ihde, Don (1990): Technology and the Lifeworld: From Garden to Earth, Bloomington: Indiana University Press.

Jonas, Hans (2006): “Toward a Philosophy of Technology”, Robert Scharff \& Val Dusek (eds): Philosphy of Technology: The Technological Condition, Malden, MA: Blackwell Publishing, 191-204.

Kittler, Friedrich (1996): “The City is a Medium”, New Literary History, 27:4, 717-729.

Kingwell, Mark (2008): Concrete Reveries: Consciousness and the City, Toronto: Viking Canada.

Kline, Stephen (2003): “What is technology?”, Robert Scharff \& Val Dusek (eds): Philosphy of Technology: The Technological Condition, Malden, MA: Blackwell Publishing, 210-212.

Lash, Scott (2002): Critique of Information, London: Sage Publications.

McLuhan, Marshall \& Fiore, Quentin (1967): The Medium is the Massage: An Inventory of Effects, New York: Bantom Books.

McQuire, Scott (2008): The Media City: Media, Architecture and Urban Space, Los

Angeles: Sage Publications.

Merleau-Ponty, Maurice (1962): Phenomenology of Perception (C. Smith, trans), London: Routledge.

Nardi, Bonnie \& O’Day, Vickie (1999): Information ecologies: Using technology with heart, Cambridge, MA: MIT Press. 